\title{
Knowledge, Attitudes and Practices (KAP) Relative to the Use of Condoms Against Sexually Transmitted Infections and HIVIAIDS in Academic Environment: February to July 2018
}

\author{
Bahati Rusimbuka Marcel ${ }^{1, \text { * }}$, Fatuma Maheshe Esther ${ }^{2}$, Bisimwa Maheshe Mathieu ${ }^{3}$, \\ Seza Bintu Diane ${ }^{3}$ \\ ${ }^{1}$ Department of Geochemistry and Environment, Goma Volcano Observatory, Goma, DR Congo \\ ${ }^{2}$ Department of Family Medicine, GESOM Hospital, Goma, DR Congo \\ ${ }^{3}$ Department of Geodesy and Deformation, Goma Volcano Observatory, Goma, DR Congo
}

Email address:

rusimbuka3@gmail.com (B. R. Marcel)

${ }^{*}$ Corresponding author

\section{To cite this article:}

Bahati Rusimbuka Marcel, Fatuma Maheshe Esther, Bisimwa Maheshe Mathieu, Seza Bintu Diane. Knowledge, Attitudes and Practices (KAP) Relative to the Use of Condoms Against Sexually Transmitted Infections and HIV/AIDS in Academic Environment: February to July 2018. International Journal of Homeopathy \& Natural Medicines. Vol. 5, No. 1, 2019, pp. 12-17. doi: 10.11648/j.ijhnm.20190501.13

Received: March 8, 2019; Accepted: April 16, 2019; Published: May 20, 2019

\begin{abstract}
This study entitled "Knowledge, attitudes and practices relating to the use of condoms in the fighting against sexually transmitted infections and HIV/AIDS in academic environment» meets the need to identify the level of knowledge, know-how and know-be of students of the ISTM-Goma on the use of condoms to fight and protect themselves from STI. This study focused on 937 students represented by 281 students of Superior Institute of Medical Techniques of Goma, registered in G1, G3, and L2 during the 2017-2018 academic year constituting our sample. It results that: students know the condom (94.3\%). Information about condom use-way remains the school, sexual partner, friends and media. Students $71.2 \%$ know male and female condoms. Almost all; $92.2 \%$ of students say that condoms protect from STI. Thus, all of the students (respondents) say that the condom is for single use. $79.7 \%$ of the students of the ISTM-Goma use condoms during sexual relations. Masculine students use more condoms (90.1\%) than feminine students $(71.9 \%)$. Age does not influence the use of condoms in relationships. Less than a quarter $(18.5 \%)$ of students at ISTM-Goma use systematically condoms during sexual relations and $42.0 \%$ use it on each occasional sexual relation. Only $32.7 \%$ of women of the ISTM regularly use condoms compared to $67.3 \%$ of men. More than half of the ISTM students use the condom for a long time (over 2 years); or 55.2\%. ISTM-Goma students impose the use of condoms to their sexual partners, at $54.1 \%$. More than half of the students cancel relation when the sexual partner refuses the use of condoms. The rip (tear) is the most quoted inconvenience by students: $66.2 \%$. Religion-belief $(48.6 \%)$ constituted the commonest barrier to condom-use. In finish; Students know condoms, ways of knowing them are school, partner friend and medias; they know two kinds of condoms: male and female. Students know that they (condoms) protect against sexual transmitted infections and HIV/AIDS, and they know how to put it. More of them pay condoms in pharmacies. More of students impose the use of condoms to partners; when partner does refuse to use it, more than the half cancel relation. Rip of condom is the high annoyance gotten. Students are favourable to the use of condoms to fight against STI and HIV/AIDS; religions don't allow their believers to use condoms.
\end{abstract}

Keywords: Knowledge, Attitudes, Practices, HIV/AIDS, Students, Sexual Transmitted Infections, ISTM, Goma 


\section{Introduction}

To all continents, Africa has a highest level of HIV/AIDS which propagate themselves the most quickly. In spite of an inflection to the decrease of their raised propagation speed these last years, the projections of the ONUSIDA and the WHO continue to make fear the worse if more energetic actions are not taken in order to face the threat.

To fight against the STI/HIV/AIDS, most African countries endowed themselves with a Struggle National Council against the AIDS and of a National Program of Struggle against the AIDS (PNLS) whose first vocation is to prevent the transmission of the HIV and to brake its propagation [3]. In order to support this reaction of countries, many international organisms multiply, by the medias actions of information, education, sensitization and social marketing not only to make become aware of the risks that the STI/HIV/AIDS represent for the sexually active population, but also to provide him to least cost, of the condoms.

The conjugated effects of the multiform interventions of education and/or sensitization and the operations of social marketing of the condom contributed to make the sexually active population become a more and more great aware of the risk to be infected by the HIV and to return the condom more close to her. However, strength is to admit that in spite of these actions, the real change of behaviours, especially the consistent use of condom in sexual intercourse to risk, take time to operate itself and to take place in the reflexes of this population, so that the threat that the continuous HIV/AIDS constitutes to weigh heavily on her. [3]

In their explanation of the resistances to the change of sexual behaviours in the African societies, several authors advanced that the programs of sensitization put until then in work in these societies arrived, nor to weaken the unfavourable prejudices whose condom is victim, nor to defeat reticence ungrounded many individuals to protect themselves at the time of the sexual intercourse. Considering the plurality of the constraints bound to the use of the condom, of the differential conditions of life of the individuals and the diversity of the sexual experiences, it imports to promote in every social context also, a program of sensitization adapted that would have for vocation, not only to inform and to educate the sexually active population on the risks to contract the STI/HIV/AIDS, but also to correct, or even to ruin, the ideas and false perceptions or non founded that a part of this continuous population to maintain on the HIV/AIDS and the condom. In clear, according to the social context, the programs of struggle against the STI/HIV/AIDS, win to integrate actions of sensitization that give the condom a more favourable perception and that increase its acceptance by the sexually active persons. [3]

Every day of the year, the humanity whole and the DRC undergo the drama provoked by innumerable deaths due to the impact of the STD in particular and the one of the infection in HIV/AIDS that affects all layers of the world population and especially the young.

According to the estimations, in $2012 ; 35,3(32,2-38,8)$ millions of people lived with the HIV in the world. We note an increase in relation to the previous years due to the increasing of people under therapy antiretroviral. On a world scale, 2,3 (1,9-2,7) millions of new infections in HIV have been signalled, either a receding of $33 \%$ in relation to the 3,4 $(3,1-3,7)$ millions of 2001 . The deaths bound to the AIDS also record a decrease, passing $2,3(2,1-2,6)$ millions in 2005 to $1,6(1,4-1,9)$ million in 2012. [7]

In Africa it's counted in 2009 more than 25 millions of seropositive and it covers about $70 \%$ of people infected on the planet. Poverty, the inequality between the sexes and the people's displacement because of a conflict or a natural disaster constitutes the socio-economic factors susceptible to increase the vulnerability of people to the infection of the HIV. [6]

In 2011 , it's estimated to $69 \%$ the cases of infections in Africa.

In the DRC, the prevalence of the HIV/AIDS was 3,5\% in $2005,4 \%$ in 2006 and in the Eastern part of the, precisely in Goma city, in 2005, the prevalence of HIV/AIDS was 5,8\%. [10]

During the year 2007, the DRC presented a prevalence of the HIV/AIDS of $4,3 \%$ in relation to the world, with $6,7 \%$ of new infections in HIV [8]; in the 2017 year, the prevalence of HIV/AIDS was $3,15 \%$ [13]. In the province of the NorthKivu, the prevalence, during this year was of 3,5\%. [8]

During the year 2011, the prevalence of the HIV in the DR Congo was of 2,57\% [9] in the general population; and all provinces were touched. Men or women, young or old, all pay a heavy tribute to this illness. The situation worsened more with the state of civil unrests that especially raged in the country to the East of the Republic. The people refugees movements and out of place (Rwanda, Burundi, Uganda), whose seroprevalence is difficult to value because of their mobility and their precariousness, as well as the too frequent acts of rape increased the impact of the AIDS in the population. [5]

Today, this pandemic made some devastations and imposed itself at the country as one of the important problems of development to the look of its speed of propagation and the devastating consequences on the plan economic and socio-sanitary of the country. [5]

Seen this tendency of increase of the prevalence with the passing of the years, the choice of a prevention means against this pandemic of the HIV/AIDS proves to be indispensable to stop the contamination of the even infected people.

This choice depends on several factors as age, the sex, the religion, the culture and the socio-professional category.

Among the ways considered for the prevention of the populations against the infections, the use of condoms stays the best but it needs a long observation within the groups of persons.

If we observe the prevalence of the HIV in the East of the DRC, it shows us that the pandemic continues to infect other people, however the use of the local methods, especially the systematic and correct use of the masculine condom made in latex is recommended as one of the main ways to interrupt 
the propagation of the STD and the HIV infection.

But, seen the difficulty that of numerous women have to convince their partner to use the masculine condom, the feminine condom offers to the women a supplementary possibility important to protect themselves and their partners of unwanted pregnancies and of the sexually transmitted infections.

The students being classified among the socio-professional categories to risk to these infections (sexually active population) and economically active, this discussion doesn't put them away.

That is how to really appreciate their knowledge, attitude and practice (know-how) on the use of the condoms, our work will articulate around following questions: Do the students have sufficient knowledge concerning the condoms?, What behaviours do they adopt facing the STI and HIV/AIDS?, Do students know the condom's utility (advantage)?, Do they use it? Which is the more used by the students between the masculine condom and the feminine condom?, How long did they use it?, Do Variables age, religion, social and personal factors influence them to not use the condoms?

\section{Materials and Methods}

\subsection{Study Area}

This study was conducted at the Goma Medical Techniques High School (ISTM-Goma). Goma is the capital city of the North-Kivu Province. Goma is administratively divided into eighteen quarters. It's limited into: at the north by the Nyiragongo territory; the south by the Lac Kivu; the East by the Republic of Rwanda and at the West party by Masisi territory.

Goma is a city of more than one million inhabitants. This study was conducted as investigation from February to July 2018.

\subsection{Study Participants and Sampling Method}

Our study was running as descriptive cross sectional, quantitative study to investigate the level of knowledge, attitude and practices of students relative to the condoms in the fighting against sexual transmitted infections and HIV/AIDS; the concerned people was student of beginning and finishing levels $\left(1^{\text {st }}\right.$ and $3^{\text {rd }}$ graduates, and $1^{\text {st }}$ and $2^{\text {nd }}$ licences) studying at ISTM-Goma during the 2017-2018 academic year. We used quantitative method because we wanted have approximate data about this topic and we associated student's factors. Statistical packages for social sciences (SPSS) and Excel were used in data entry and analysis.

\subsection{Sample Size and Data Collection Technique and Analysis}

The study sample was taken on basis of $30 \%$ of the total of the total population which was 937 students. As they are composed to many categories of people; grouped on basis of level (promotion); we have considered for every category a group representing $30 \%$. The sample's size was constituted of 281 students.

The data was collected using self-administered questionnaires to students. For those students who were ready and disposed to answer, the questionnaire was given to them and they filled it up by themselves freely.

All data were analysed in PASW 18 (Predictive Analytics Software) and tables were performed in Microsoft Excel.

\section{Results}

\subsection{Socio Demographic Determinants}

A total of 281 students had participated to the study, majority of respondents $(n=182)$ were masculine $(64,8 \%)$. Although, majority of participants $(n=208)$ were single $(74 \%)$, married represented $26 \%$. The age group of 21-25 years $(n=159)$ was the more represented $(56,6 \%)$; still significance portion of participants were either $26-30$ years old $(25,3 \%)$ or $18-20$ years $(14,6 \%)$. The protestant religion $(n=105)$ was the more representative $(37,4 \%)$; then catholic $(n=84)$ which represented $29,9 \%$; Kimbanguist $(n=28)$ came on the third place $(10 \%)$; Moslem represented $8,2 \%$ of our respondents; other religions had been represented at less than $8 \%$.

Table 1. Socio-demographic characteristics of students (respondents) $(n=281)$, ISTM-Goma, 2018.

\begin{tabular}{llll}
\hline \multirow{2}{*}{ Variable } & Characteristics & & \\
\cline { 2 - 4 } & Category & Frequency & Percentage (\%) \\
\hline \multirow{2}{*}{ Sex } & MASCULINE & 182 & 64,8 \\
Marital & FEMININE & 99 & 35,2 \\
status & SINGLE & 208 & 74,0 \\
& MARIED & 73 & 26,0 \\
& CATHOLIC & 84 & 29,9 \\
& PROTESTANT & 105 & 37,4 \\
Religion & MOSLEM & 23 & 8,2 \\
& WAKENING CHURCH & 8 & 2,8 \\
& KIMBANGUIST & 28 & 10,0 \\
& ADVENTIST & 14 & 5,0 \\
& OTHERS & 19 & 6,8 \\
Age & 18-20 years & 41 & 14,6 \\
(Years) & 21-25 years & 159 & 56,6 \\
& 26-30 years & 71 & 25,3 \\
& 31 and more & 10 & 3,6 \\
Promotion & G1 & 114 & 40,6 \\
& L2 & 105 & 37,4 \\
\hline
\end{tabular}

Source: Field data 2018

\subsection{Knowledge of Condom}

The quasi-totality $(n=265)$ of our investigated know the condom $(94,3 \%)$ and $5,7 \%$ of investigated students didn't know condom. Most of them had knew it from friend $(23,8 \%)$; sexual partner $(24,2 \%)$; medias $(21,0 \%)$ or to school $(24,6 \%)$. A lot of number of students investigated $(n=200)$ know two types of condoms $(71,2 \%)$ : the male and the female; only $23,1 \%$ of them know the male (masculine) condom only. To those who know the condom; 259 of them said that condom protects against STI and HIV/AIDS $(92,2 \%)$. Many students $(n=224)$ said that they had learned how to put the condom $(79,7 \%)$. 
Table 2. Knowledge of condom.

\begin{tabular}{llll}
\hline \multirow{2}{*}{ Variable } & Characteristics & & \\
\cline { 2 - 4 } & Category & Frequency & Percentage (\%) \\
\hline Knowledge of & Yes & 265 & 94,3 \\
condom & No & 16 & 5,7 \\
& Friend & 67 & 23,8 \\
& Sexual partner & 68 & 24,2 \\
Way of knowing & Parents / familiar & 2 &, 7 \\
& Medias & 59 & 21,0 \\
Types of & to school & 69 & 24,6 \\
condoms & M & 65 & 23,1 \\
Condoms protect & M+F & 200 & 71,2 \\
Know how to put & Yes & 259 & 92,2 \\
condom & Yes & 6 & 2,1 \\
& No & 224 & 79,7 \\
\hline
\end{tabular}

Source: Field data 2018

\subsection{Practice of Students}

According to the result of the investigation, more of the student $(n=224)$ who were free and had agreed to participate to our study, after saying that they know the condoms, they said that they use condoms $(79,7 \%) ; 42,0 \%$ of students use it on each occasional sexual relation, while only $18,5 \%$ use it regularly/systematically and, $19,2 \%$ use it even if the sexual partner demand or recommend him/her to its use. For investigated students who use condoms, $55,2 \%$ use it for a long time $(\mathrm{n}=155)$. The pharmacy stills a higher place $(n=110)$ of procurement of condoms to the students $(39,1 \%)$. We are to note that $54,1 \%$ of students impose the use of condoms to their sexual partners; while 7,8\% know that it is the custom and said that it is their habit to use condoms on each sexual relation.

Table 3. Practice of students.

\begin{tabular}{|c|c|c|c|}
\hline \multirow{2}{*}{ Variable } & \multicolumn{3}{|l|}{ Characteristics } \\
\hline & Category & Frequency & Percentage (\%) \\
\hline \multirow{3}{*}{ Do you use condom } & Yes & 224 & 79,7 \\
\hline & No & 44 & 15,7 \\
\hline & Regularly / Systematically & 52 & 18,5 \\
\hline \multirow[t]{2}{*}{ On what occasion (when) } & Occasional sexual intercourse & 118 & 42,0 \\
\hline & onto the demand of the sexual partner & 54 & 19,2 \\
\hline \multirow{4}{*}{ From how long } & Less than 6 mounths & 18 & 6,4 \\
\hline & there is 1 year & 30 & 10,7 \\
\hline & for 2 years & 21 & 7,5 \\
\hline & For a long time & 155 & 55,2 \\
\hline \multirow{5}{*}{ Where do you procure them } & at the pharmacy & 110 & 39,1 \\
\hline & from an authorized distributor & 42 & 14,9 \\
\hline & at the hospital & 49 & 17,4 \\
\hline & in a quarter kiosk & 5 & 1,8 \\
\hline & to a friend & 16 & 5,7 \\
\hline \multirow{3}{*}{ Do you impose its use } & Yes & 152 & 54,1 \\
\hline & No & 64 & 22,8 \\
\hline & My partner knows that it's the custom & 21 & 7,5 \\
\hline
\end{tabular}

Source: Field data 2018

\subsection{Attitude of Students}

Investigated students said that when the sexual partner refuses the use of condom they cancel to relation 56,7\%; whereas $21,9 \%$ of students declared to pass on act without condom. More of students $(n=147)$ have never got annoyance during sexual relations using condoms $(65,6 \%)$; only $34,4 \%$ had got it. Among these one who had got annoyance with the condoms, $66,2 \%$ assisted to a rip of condoms $(n=51) ; 18,2 \%$ had been victims of slip and $14,3 \%$ had seen their erection breakdown. In case of rip of condom; only $10,3 \%$ of students continue their relation putting an other condom; $12,5 \%$ end the sexual act; whereas $17 \%$ of students takeout firstly the fragments of condoms from the sex (vagina), and 0,4 continues without putting an other condom. $78,5 \%$ of investigated students are favourable to the use of condoms against the STI; while $21,5 \%$ aren't. About the half of investigated who don't use condom $(n=51)$ had given a reason of the non use of condom saying that their religion (belief) forbids them it $(48,6 \%) ; 38,1 \%$ declared that it reduces (decreases) the sensibility (pleasure); 4,8\% don't have access to the condom. More than the half of investigated $(\mathrm{n}=144)$ had never contracted Sexual Transmitted Infections (STI) 51,2\%; whereas $48,8 \%$ of investigated students had contracted it $(n=137)$.

Table 4. Attitude of students to the use of condoms.

\begin{tabular}{|c|c|c|c|}
\hline \multirow{2}{*}{ Variable } & \multicolumn{3}{|l|}{ Characteristics } \\
\hline & Category & Frequency & Percentage (\%) \\
\hline \multirow{3}{*}{ When partner refuses the condom } & I annul the sexual act & 127 & 56,7 \\
\hline & I pass on act without condom & 49 & 21,9 \\
\hline & Indifferent (it depends on his/her willingness) & 48 & 21,4 \\
\hline \multirow{2}{*}{ Have got annoyance whith condom } & Yes & 77 & 34,4 \\
\hline & No & 147 & 65,6 \\
\hline
\end{tabular}




\begin{tabular}{|c|c|c|c|}
\hline \multirow{2}{*}{ Variable } & \multicolumn{3}{|l|}{ Characteristics } \\
\hline & Category & Frequency & Percentage (\%) \\
\hline \multirow{5}{*}{ Which one } & BREAKDOWN OF ERECTION & 11 & 14,3 \\
\hline & RIP & 51 & 66,2 \\
\hline & SLIP & 14 & 18,2 \\
\hline & Tickle & 1 & 1,3 \\
\hline & To takeout firstly the fragments & 38 & 17,0 \\
\hline \multirow{4}{*}{ Attitude on rip } & Continue puting an other & 23 & 10,3 \\
\hline & Continue without puting an other & 1 &, 4 \\
\hline & End the sexual act & 28 & 12,5 \\
\hline & It never happened to me & 134 & 59,8 \\
\hline \multirow{3}{*}{$\begin{array}{l}\text { Are you favourable to the use of the } \\
\text { condoms in struggle against the STI? }\end{array}$} & Yes & 219 & 78,5 \\
\hline & No & 60 & 21,5 \\
\hline & The condom decreases the sensitivity / pleasure & 40 & 38,1 \\
\hline \multirow{4}{*}{ Reason of non use of condom } & Refusal of the partner & 7 & 6,7 \\
\hline & I lose the erection while putting the condom (breakdown of erection) & 2 & 1,9 \\
\hline & Inaccessibility to the condom & 5 & 4,8 \\
\hline & My belief forbids me it & 51 & 48,6 \\
\hline \multirow{2}{*}{ Had contract STI } & Yes & 137 & 48,8 \\
\hline & No & 144 & 51,2 \\
\hline
\end{tabular}

Source: Field data 2018

\section{Discussion, Strength and Limitation}

\subsection{Discussion}

This study attempted to describe and determine the "knowledge, attitudes and practices relating to the use of condoms in the fight against sexual transmitted infections and HIV/AIDS in academic environment" at ISTM-Goma (Goma Medical Technics High School). The study focused on 937 students of this high school who were represented by a sample of 281 students registered in the first, third years of graduate and the second (last) year of licence during the 2017-2018 academic year.

The quasi-totality of students who had participated to this study know condom $(94,3 \%)$; these results are superior to those founded by the URD of Lomé University (70\%) in 2011 [3]; they know it from School, sexual partner, friend and medias. Three quarter $(71,2 \%)$ of them know two kinds of condoms: the male and the female. More of the students $(92,2 \%)$ know that condoms protect against sexual transmitted infections and HIV/AIDS, our results aren't so different to the ROCARE's (91,7\%) in march 2007 [2]; they know how to put it $(79,7 \%)$, this is higher than those of Mahamane Sanil (22,44\%).

The totality of our respondents expressed on the reuse of condoms said that it is for a unique (single) use; our results are superior to those founded in a KAP study realised by Dr F. Toudeft in Algeria: $75 \%$ of students declared that condom is for single use. [1]

Students $79,7 \%$ declared that they use condoms, results near percentage founded by Sobze Martin Sanou and coll. $(76 \%)$, and higher than that of Mahamane Sanil LA/Niger (58\%) [11]; almost half of investigated students (42,0\%) use condoms on each occasional sexual relation: these results are less than those founded in France [4] on the third national investigation on student's health $(78 \%)$ but less than those of Adinma JIB (22,1\%) in Nigeria [12]; 18,5\% use it systematically, this result is less than the Adinma JIB's who find $42,1 \%$ [12]; more than the half use it from a long time. They procure them from a pharmacy $(39,1 \%)$, a hospital $(17,4 \%)$, an authorized distributor $(14,9 \%)$. More of those who use condoms $(54,1 \%)$ impose its use to their partners.

When partner refuses the use of condom in sexual relation more than the half of students $(56,7 \%)$ decide to cancel the relation, others $(21,9 \%)$ consume sex without condoms and, some $(21,4 \%)$ are indifferent. Only $34,4 \%$ of students had got annoyance in the use of condoms. The rip of condom stays the high annoyance $(66,2 \%)$ gotten by students. In case of rip partners takeout firstly the fragments $(17,0 \%)$; whereas $12,5 \%$ end the sexual act. Students are favourable to the use of condoms to fight against STI and HIV/AIDS (78,5\%). Almost the half of students who don't use condom $(48,6 \%)$ said that the main barriers its use were religion, these results are not different to those founded by Mahamane Sanil LA et all. (46.46\%) [11]; the condom decrease the sensibility $(38,1 \%)$, and the refusal of partner to $6,7 \%$, Mahamane find 7,55\% [11], $51,2 \%$ of investigated students have never contract STI. Find

\subsection{Strength and Limitation}

This study can be interpreted in light of its strengths and limitations. The use of questionnaires, the fact that this study assessed individual factors, including knowledge and attitude of students, as well as variable in this study can be considered as a major strength of our study. However, other factors like practices and socio-demographics determinants have been associated in this study to determine and verify the degree of the use of condoms against STI and HIV/AIDS. In addition, not using enough literatures about this topic due to the unavailability of published data in the study area and all the region (province) could be mentioned as a limitation.

\section{Conclusion and Recommendation}

\subsection{Conclusion}

Based on the research, we conclude: that students know 
condoms, ways of knowing it are school, partner friend and medias; they know two kinds of condoms: male and female. Students know that condoms protect against sexual transmitted infections and HIV/AIDS, and they know how to put it. They use condoms from long time, some of them on each occasional relation, systematically. More of them pay condoms in pharmacies. More of students impose the use of condoms to partners; when partner does refuse to use it, more than the half cancel relation. About $35 \%$ of respondents who use condoms had got annoyance when consuming sex; rip of condom is the high annoyance gotten. Students are favourable to the use of condoms to fight against STI and HIV/AIDS; religions don't allow their believers to use condoms.

\subsection{Recommendation}

Government and NGOs should develop strategies to improve and boost the use of condoms adding or improving distributors; government should impose to all pharmacists to distribute condoms, not to sell them. Government should order to the church (religion) responsible to allow the use of condoms. Each student should impose the use of condoms in sexual relation to avoid sexual transmitted infections and HIV/AIDS.

\section{Acknowledgements}

Thanks to the participants who had completed the survey (students of ISTM-Goma), the institution's management committee, students for distributing survey.

\section{References}

[1] Dr. F. Toudeft: Etude sur les connaissances, attitudes et comportements des jeunes universitaires en matière de l'infection à VIH/SIDA: Evaluation des actions de proximité; 2010.
[2] ROCARE: Perceptions, Attitudes et Pratiques face au VIH/SIDA dans les universités de Ouagadougou, de BoboDioulasso et de Koudougou: la réponse de l'intelligentsia burkinabé est-elle adéquate ?; Mars 2007.

[3] URD (2006) «Prévalence du VIH chez les jeunes, connaissances attitudes et pratiques en matière de VIH/SIDA auprès de la population générale au Togo et sur la disponibilité et l'accès au préservatif»; Rapport d'étude, Lomé, Mars 2011.

[4] LMDE Santé des Etudiants: $3^{\text {ème }}$ Enquête Nationale sur la Santé des Etudiants, Novembre 2010-janvier 2011.

[5] Médecins d'Afrique: «Sensibilisation VIH à Goma/ Nord Kivu dans le cadre de la Journée Mondiale de Lutte contre le VIH», Rapport d'activités, Décembre 2011.

[6] ONUSIDA; Rapport sur l'épidémie mondiale de SIDA; 2009.

[7] ONUSIDA; Rapport sur l'épidémie mondiale de SIDA; 2013.

[8] PNMLS: LUTTE CONTRE LE VIH ET LE SIDA EN RDC, REALISATIONS ET DEFIS, 2008.

[9] PNMLS: Rapport d'activité sur la riposte au VIH/SIDA en RD Congo, 2012.

[10] Province du Nord-Kivu: Document de stratégie de réduction de la pauvreté, décembre 2005.

[11] Mahamane Sanil LA, Jinson L, Mahamadou Kamaye I, Djibo H. Condoms Use Among Resident Students at the University Abdou Moumouni Campus in Niamey/Niger. Austin J Public Health Epidemiol. 2014; 1 (1): 1002.

[12] Adinma JIB, Adinma ED, Eke NO, Umeononihu OS (2016) Condom-Use by Students in a Higher Educational Institution in South Eastern Nigeria. J Comm Pub Health Nurs 2: 127. doi: $10.4172 / 2471-9846.1000127$.

[13] République Démocratique du Congo, Ministère de la Santé, PNLS, Rapport annuel 2017. 